\title{
Perspectivas del turismo en el Barrio Mágico San Pedro Atocpan en función de su condición como espacio periurbano
}

\author{
Adriana Dennise Rodríguez Blanco ${ }^{1}$
}

Resumen: El turismo es fundamental en la economía de México. En la Ciudad de México opera desde 2011 el programa Barrios Mágicos Turísticos, e incluye un espacio periurbano, San Pedro Atocpan, que, gracias al mole, destaca como referente gastronómico de la capital. El objetivo principal de este artículo es comparar la visión del turismo desde tres posturas: desde la academia, se encontró que las actividades ofertadas pueden llamarse recreativas; desde la postura gubernamental, la prioridad resultó ser la promoción de cualidades únicas; y desde la percepción de los visitantes y lugareños, la localidad se construye desde el hecho de que viven diferente, en donde el turismo aún no tiene un papel bien definido.

Palabras clave: San Pedro Atocpan, Barrio Mágico Turístico, mole, espacio periurbano

\section{Perspectivas do turismo no Bairro Mágico San Pedro Atocpan em função da sua condição de espaço periurbano}

Resumo: O turismo é fundamental na economia do México. Na Cidade do México, o programa Barrios Mágicos Turísticos tem operado desde 2011, incluindo um espaço periurbano, San Pedro Atocpan, que, graças ao mole, se destaca como referência gastronômica da capital. O principal objetivo deste artigo é comparar a visão do turismo a partir de três posições: da academia, na qual se verifica que as atividades oferecidas podem ser classificadas como recreativas; do ponto de vista governamental, a prioridade resultou na promoção de qualidades únicas; e da percepção de visitantes e residentes locais, na qual o local se constrói a partir de um distinto modo de vida, em que o turismo ainda não encontra um papel bem definido.

Palavras-chave: San Pedro Atocpan, Barrio Mágico Turístico, mole, espaço periurbano

\section{Perspectives of tourism in Magical Touristic District San Pedro Atocpan based on its condition as a peri-urban space}

\begin{abstract}
Tourism is essential in Mexican economy. In Mexico City, since 2011, Magical Touristic Barrios program operates, and it includes a periurban space, San Pedro Atocpan, that, thanks to the mole, it is a gastronomical reference in the capital city. The main task in this paper is to compare the vision of tourism in three positions: from academy, it was found that the offered activities may be catalogued as recreational; from government position, the priority was the promotion of unique qualities; and from both visitors and residents, the place is built from the fact that they live different, where tourism has not a defined role yet.
\end{abstract}

Keywords: San Pedro Atocpan; Magical Touristic Barrios; mole; peri-urban spaces

Recebido: janeiro de 2018. Aceite: março de 2018.

${ }^{1}$ Licenciada en Geografia pela Facultad de Filosofía y Letras, Universidad Nacional Autónoma de México/UNAM. Email: cyoux16@gmail.com 


\section{Introducción}

El turismo ha estado presente en la historia del hombre ilustrado (Sue, 1987), pero a partir de la reactivación económica en el periodo de posguerra, en la segunda mitad del siglo XX, creció de manera exponencial. En la era de la globalización se ha popularizado la cultura del ocio, pues hoy en día el esfuerzo productivo cotidiano y el ocio constituyen atributos inseparables de las personas, lo que acelera la difusión de manifestaciones culturales (Vinuesa, Marchante \& Hernández, 2008); incluso, autores como Turner y Ash (1991) observan la creciente tendencia de comercializar la necesidad humana de viajar.

Una variable que ha aparecido en los estudios recientes sobre turismo, y que responde a la diversificación de la oferta, es la magia como elemento discursivo para consolidar destinos turísticos. Para Picard (2011, p. 2), la magia atribuida a los destinos turísticos es un "elemento constitutivo del pensamiento moderno y las formas de vida social que éste ha delineado (...) crucial para mantener y renovar los destinos, que legitiman el orden político y moral de la vida moderna".

La articulación del sector turístico en diversos países de Latinoamérica responde a la lógica neoliberal que permea todas las actividades económicas (Vich, 2006), por lo que la adopción de la magia como motor de funcionamiento de diversos programas gubernamentales en México resulta un caso de especial interés, ya que ha terminado por consolidar la apuesta de diversos gobiernos de este país -fundamentalmente aquellos de la década de 1980- para convertir el turismo en un proyecto nacional.

El siglo XXI trajo consigo programas concretados gracias a la magia. En 2001, el Programa Nacional de Turismo definió por primera vez una política de turismo cultural para el país, al establecer "acciones que evolucionen la puesta en valor de los sitios arqueológicos, coloniales, manifestaciones de arte y tradiciones, monumentos y edificios históricos, así como otras expresiones culturales..." (Fernández, 2016). El Programa Pueblos Mágicos es el mejor ejemplo de la adopción institucional de uno de los esquemas de ganancias más rentables: la promoción del turismo.

Este programa se basó en la premisa de "revalorar a un conjunto de poblaciones del país que siempre han estado en el imaginario colectivo de la nación en su conjunto y que representan alternativas frescas y diferentes para los visitantes nacionales y extranjeros" (SECTUR, 2001), de forma tal que los atributos de las comunidades permitan un desarrollo sustentable gracias a su singularidad, carácter y autenticidad. Las consecuencias de este programa han sido muy discutidas; particularmente, en cuanto al turismo cultural, se ha señalado su capacidad de catalizar fenómenos de turistificación y mercantilización del patrimonio (Delgadillo, 2015), mientras que por otro podría permitir una revalorización e identidad de los atractivos (Castañeda, 2012).

La Ciudad de México se excluyó del programa federal al no cumplir con el criterio establecido de población máxima permitida (20.000 habitantes), por lo que la Secretaría de Turismo local (SECTUR-DF), para compensar esa situación, durante la jefatura de gobierno encabezada por Marcelo Ebrard aprobó en 2011 la creación del Programa Barrios Mágicos Turísticos (PBMT), cuya dinámica es similar a la del programa federal, puesto que opera con los mismos principios de resaltar lo diferente de la ciudad.

En la delimitación de perímetros del PBMT surgen dos notables excepciones: de las 21 áreas contempladas en el programa gracias a su resistencia a la urbanización, San Andrés Mixquic, en el límite oriental de la delegación Tláhuac, y San Pedro Atocpan, al norte de la delegación Milpa Alta, son espacios periurbanos, lo que los distingue del resto de Barrios Mágicos Turísticos, localizados dentro de la mancha urbana (figuras 1 y 2). San Pedro Atocpan, además, resulta de particular interés al ser uno de los pueblos donde se concentra la infraestructura y la actividad económica de la delegación menos urbanizada de la Ciudad de México.

Figura 1. San Andrés Mixquic ofrece como atractivo turístico su festividad originaria más importante, el Día de Muertos.

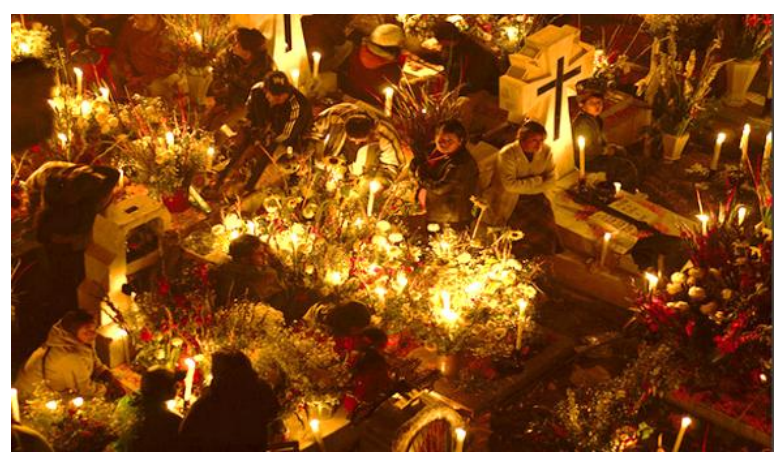

Fuente: Portal de turismo https://masmexico.com.mx/las-tradiciones-de-dia-de-muertos-en$\underline{\text { mixquic/ }}$

Figura 2. San Pedro Atocpan atrae visitantes gracias a su variada gastronomía, centrada en el mole (elaborado de manera local). Ambos lugares representan espacios 
de resistencia a la urbanización, al conservar sus tradiciones.

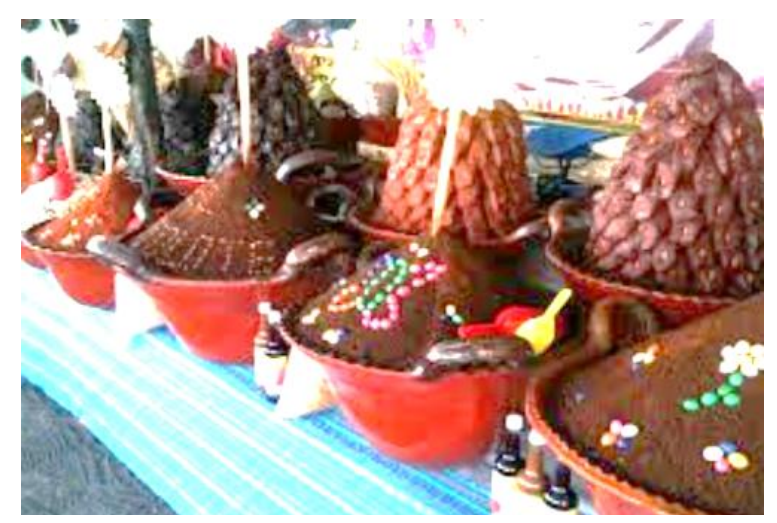

Fuente: Portal de turismo https://turespacio.com/ferianacional-del-mole/

Al reconocer la particularidad espacial de la localidad, así como su potencial turístico y su resistencia a la urbanización, se planteó un trabajo que se sustentó en las siguientes preguntas de investigación:

1. ¿Cuál es la percepción de los habitantes de San Pedro Atocpan acerca del turismo en su localidad?

2. ¿Qué cambios, sociales, espaciales y económicos, han ocurrido en la localidad a partir del nombramiento como Barrio Mágico Turístico?

3. ¿De qué manera la promoción turística de San Pedro Atocpan contribuye a su vinculación con el resto de la ciudad?

\section{Posiciones cognoscitivas}

La discusión teórica sobre el turismo es muy amplia. Desde su concepción como industria, en la que se define como un conglomerado que integra corporativos, empresas privadas, instituciones de gobierno y grupos sociales (Contreras \& Muñoz, 2014), hasta otras definiciones que lo etiquetan como una forma de imperialismo (Nash, 1992), un fenómeno exógeno a las sociedades que lo albergan (Nicolas, 2006), o una institución política de la modernidad (Picard, 2011), se trata de un término muy utilizado en ciencias sociales, pues es una actividad económica cada vez más globalizada. En el caso de América Latina ha cobrado relevancia, en especial el turismo cultural como alternativa a las opciones tradicionales de sol y playa, debido a la gran riqueza patrimonial de esas naciones (CONACULTA, 2013).

Otras definiciones permiten atisbar la transversalidad de la actividad turística en la sociedad, la economía y el territorio, por ejemplo, se le denominó como "un sistema de actores, de prácticas y de lugares que tiene por objetivo permitir a los individuos desplazarse para su esparcimiento fuera de su lugar de vida habitual" (Equipe MIT, 2002, p. 31); mientras que la definición más reciente de la Organización Mundial de Turismo (OMT) lo caracteriza como "un fenómeno social, cultural y económico, que involucra el desplazamiento de personas hacia países o lugares fuera de su entorno habitual para propósitos personales, profesionales o de negocios" (OMT, 2012).

El concepto turismo ha evolucionado, así como las perspectivas desde las que se analiza. En 1987, por ejemplo, fue analizado por R. Boullón como un sistema de oferta y demanda; para Urry (2002) lo estudió como parte de la oposición entre trabajo y ocio, con los desplazamientos como elemento básico para construir el concepto; en 1994 la OMT lo definía con una temporalidad mayor a un día y menor a un año consecutivo, separando así las actividades de ocio de las turísticas (Soneiro, 1991), mientras que las posturas contemporáneas ya no son excluyentes en cuanto a temporalidad y hablan de una diversificación de las actividades, que ahora se perfilan para propiciar la búsqueda de experiencias auténticas (Cohen, 2005).

$\mathrm{Al}$ ser una actividad productiva, el turismo no queda exento del sistema de producción, por lo que debe analizarse el cambio histórico que ha sufrido, pues ha sido permeado por el neoliberalismo en forma de marketing, que busca incrementar la cantidad y calidad de los bienes y servicios consumidos por los individuos, denominados commodities $i$ (Higgins-Desbiolles, 2006; Mosedale, 2016), por lo que podría definirse como "un proceso global de mercantilización y consumo, que implica flujos de personas, capitales, imágenes y culturas" (Fraga, Khafash \& Ordoñez, 2015, p. 37).

Su estudio desde la disciplina geográfica se ha construido desde el análisis del territorio, por lo que tiene la capacidad de aportar una mejor comprensión de la relación sociedad-espacio (Nicolas, 2006), pero también ha incorporado nuevas perspectivas, como aquella proveniente de la visión de sus visitantes o de quienes residen en los espacios turísticos (Sizzo, 2012); aportaciones desde el enfoque empresarial que se sirve de herramientas auxiliares como el marketing, o desde una concepción crítica, que analiza la distribución de la riqueza entre los países receptores y los 
emisores (Turner \& Ash, 1991).

En cuanto a los espacios periurbanos, se trata de una conceptualización en construcción. La tipificación clásica de las localidades -en función de los servicios y población - durante mucho tiempo se limitó a dos categorías: rural y urbano. Dentro de la redefinición del marco conceptual empleado en la disciplina geográfica ha surgido el término espacio periurbano, que hace referencia a "una interfase entre el sistema urbano y el entorno natural, caracterizado por ser un área de reserva urbana y cinturón verde, estructurada desde, por y para la ciudad" (Velázquez, 2002, p. 54). Esta particularidad espacial es compatible con la realidad de San Pedro Atocpan, (figura 3), por lo que se utiliza esta categoría de análisis para caracterizar la localidad.

Figura 3. La localización de San Pedro Atocpan, en la franja menos urbanizada de la ciudad, así como los usos de suelo que presenta (alternancia entre usos agropecuarios y habitacionales dentro de un área catalogada como suelo de conservación) permiten inferir su carácter periurbano

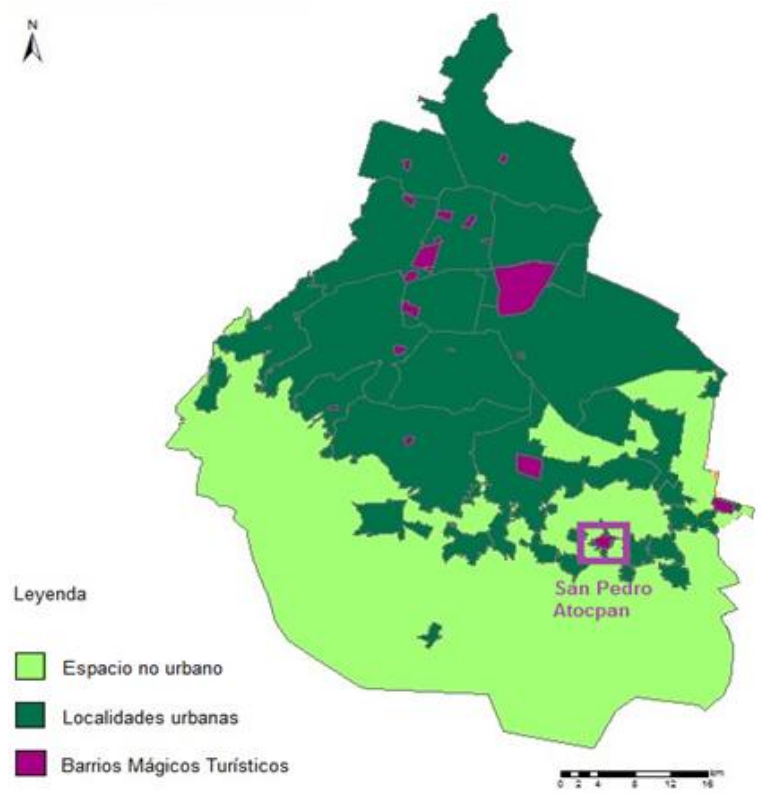

Fuente: Modificado de Blanco (2017)

\section{San Pedro Atocpan en el imaginario colectivo de la Ciudad de México}

San Pedro Atocpan -que en náhuatl significa "sobre tierra fértil"- se localiza en Milpa Alta, Ciudad de México, y vive una realidad diferente de las características que rigen en casi toda la metrópoli, tanto desde el punto de vista económico como el ambiental, social y cultural; pues en esta delegación aún son importantes las actividades primarias, además de que cuenta con el
$100 \%$ de su territorio como suelo de conservación, lazos comunitarios y organización social fuerte, así como elementos identitarios únicos (figura 4), dentro de los cuales se encuentra la elaboración del mole.

Figura 4. Desde 1976, las familias que elaboran el tradicional platillo del mole se organizan en una feria anual para que los visitantes disfruten las variedades que ellos mismos han perfeccionado. En la edición de 2007, esta enorme cazuela de barro a la entrada del pueblo presumía el título de Capital del mole, mismo que aún se utiliza para promoción turística.

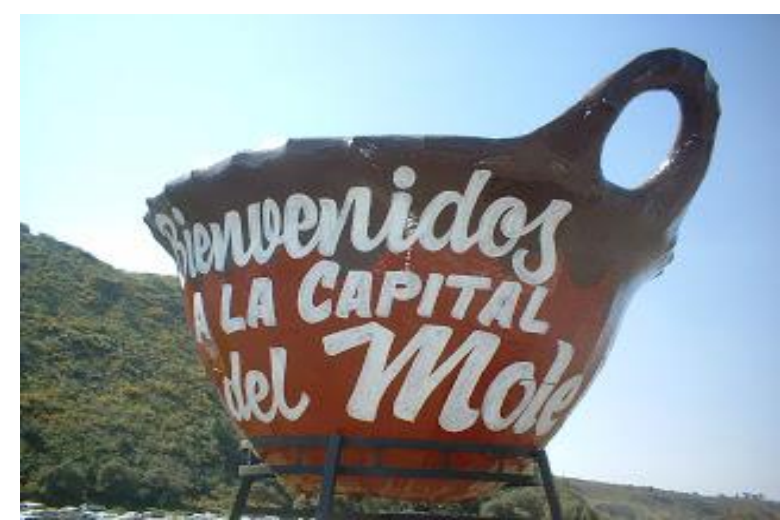

Fuente:

http://universonublado.blogspot.mx/2007/10/feriadel-mole-de-san-pedro-atocpan.html

Esta delegación destaca del conjunto metropolitano desde el punto de vista histórico (figuras 5 y 6). El origen de este asentamiento ocurrió antes de la llegada de los mexicas al Valle de México; de raíces chichimecas y en frecuente alianza con los xochimilcas, el poblado resistió los procesos de anexión al imperio azteca y a la posterior colonización española. No obstante, en 1529 la población se convirtió al catolicismo a cambio de mantener las propiedades comunales ya establecidas (INAFED, 2005), y hasta 1854 perteneció al Estado de México, aunque en la época de Juárez se incorporó a la capital, bajo las figuras administrativas de los ayuntamientos de Milpa Alta y Atocpan.

Debido a su cercanía con Morelos, el territorio milpaltense fue importante como puente comercial entre el Valle de México y el de Morelos; asimismo, en la época de la Revolución Mexicana tuvo gran importancia debido a que fue el lugar en el que se ratificó el Plan de Ayala, en el pueblo de San Pablo Oztotepec (Custardoy, 2003; Wacher, 2006). Las actividades económicas más importantes hasta inicios del siglo XX fueron la producción de hortalizas, la elaboración y venta de pulque, comercialización de carbón y aprovechamiento forestal. 
En 1928 se documentaron los inicios de la industria del mole en San Pedro Atocpan, platillo traído del exteriorii, con el cual comenzó a surgir una actividad económica relevante que sirvió de alternativa a la agricultura, que estaba arraigada en general en toda la demarcación. Desde la década de 1940, la delegación comenzó a urbanizarse, se conformó una estructura artesanal productora de alimentos con orientación al comercio y el turismo, y se inició una mayor comunicación con el resto de la ciudad a través de Atocpan, lo que facilitó el establecimiento de la producción comercial de nopal hacia el resto de la ciudad (Wacher, 2006).
Milpa Alta es innegable, incluso en la actualidad, ya que contribuye con el $100 \%$ de la producción de nopal, el $38.2 \%$ de maíz grano y el $14.1 \%$ de la avena forrajera comercializados en la Central de Abastos de la Ciudad de México (PDDU, 2011: 29); no obstante, Atocpan comenzó a desapegarse de la actividad agrícola a lo largo del siglo XX gracias al despunte de la elaboración artesanal del mole.

Figura 5 y 6. El Zócalo de la Ciudad (izquierda) y Milpa Alta (derecha) en la década de 1920. Hay un claro contraste entre un paisaje plenamente urbanizado, y con transporte propio de la época, y otro de carácter rural, en el que tiene una gran relevancia la organización comunitaria.

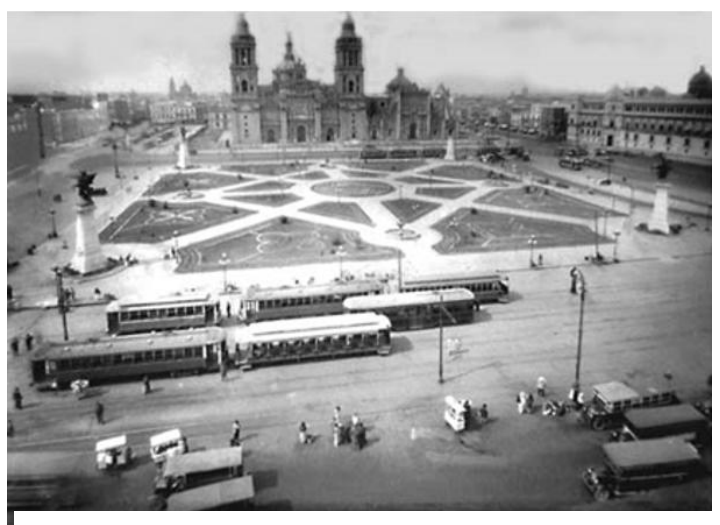

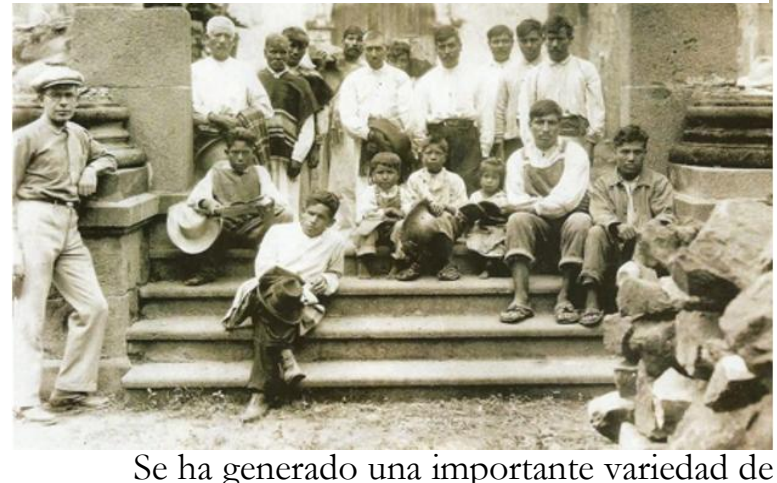

Se ha generado una importante variedad de

Fuentes: http://www.mexicomaxico.org/zocalo/zocaloEV.htm y https://www.pinterest.com/pin/491947959275329287/

Debido a su cercanía con Morelos, el territorio milpaltense fue importante como puente comercial entre el Valle de México y el de Morelos; asimismo, en la época de la Revolución Mexicana tuvo gran importancia debido a que fue el lugar en el que se ratificó el Plan de Ayala, en el pueblo de San Pablo Oztotepec (Custardoy, 2003; Wacher, 2006). Las actividades económicas más importantes hasta inicios del siglo XX fueron la producción de hortalizas, la elaboración y venta de pulque, comercialización de carbón y aprovechamiento forestal.

En 1928 se documentaron los inicios de la industria del mole en San Pedro Atocpan, platillo traído del exterioriii, con el cual comenzó a surgir una actividad económica relevante que sirvió de alternativa a la agricultura, que estaba arraigada en general en toda la demarcación. Desde la década de 1940, la delegación comenzó a urbanizarse, se conformó una estructura artesanal productora de alimentos con orientación al comercio y el turismo, y se inició una mayor comunicación con el resto de la ciudad a través de Atocpan, lo que facilitó el establecimiento de la producción comercial de nopal hacia el resto de la ciudad (Wacher, 2006).

La importancia de la actividad agrícola en este platillo, que comenzó a ofertarse a los visitantes que llegaban en fines de semana a los restaurantes y expendios especializados gracias a la inauguración de la nueva carretera XochimilcoOaxtepec en 1975 (PDDU, 2011).

Otro factor que aumentó la afluencia de visitantes a la localidad fue la instauración de la Feria del Mole, iniciada en 1976 y continuada de manera anual hasta la actualidad, lo que ha resultado en una fuente de empleo estable para los lugareños, que encontraron en la elaboración del mole una opción para no desplazarse a trabajar en otras delegaciones; de acuerdo a diversos medios periodísticos iv, más del $90 \%$ de los trabajadores de San Pedro Atocpan se dedica a la preparación y venta del mole, quienes distribuyen el $60 \%$ de la producción de mole de todo el país (Hursh, 2008).

Por otra parte, el gobierno, tanto en nivel estatal como local, ha tomado acciones y emitido publicaciones que permiten inferir que se busca impulsar una actividad de carácter turístico, tomando al mole como el factor detonante para llevarla a cabo, pues a partir de 2011 - año en que se concretó el programa Barrios Mágicos Turísticos- se ha enfatizado el potencial de la localidad en este rubro, con la organización de

PatryTer • ISSN: 2595-0169 • vol $1 \bullet$ n. $1 \bullet \operatorname{março~} 2018 \bullet$ pp. 68-80 • Artigo 
eventos de corte cultural además de la Feria del Mole, como, por ejemplo, el Tianguis Turístico.

\section{Metodología}

La geografía de la percepción ha tenido un desarrollo histórico complejo. Surgida como una alternativa dentro de los estudios de lo urbano, en la década de 1950, se fortaleció como enfoque al definir el espacio en función del valor que se le da desde cada individuo o colectivo social (Muñoz, 2008), con fuertes bases en la psicología. En 1960, la publicación de La imagen de la ciudad, de Kevin Lynch, concretó la elaboración de una metodología para entender la conciencia perceptiva que tenían los habitantes de una ciudad, mediante el uso de mapas mentales (Lynch, 1998). Esta obra sentó el antecedente para que surgieran nuevas maneras de conocer los espacios, más allá de la cartografía formal.

En México, la geografía de la percepción se ha utilizado en varios campos: desde perspectivas electorales, ambientales, de prestación de servicios de salud, transporte, inseguridad y discriminación; en cuanto a temas de turismo, se ha empleado en trabajos sobre percepción comunitaria, de experiencias turísticas, y metodologías cualitativas aplicadas a casos particulares, aunque en general es un enfoque que apenas comienza a despuntar en los estudios turísticos (Blanco, 2017).

El primer intento de combinar aportes de métodos cualitativos y cuantitativos se presentó en 1971, en el trabajo de Metton, que buscó conocer la percepción de niños y adolescentes acerca de los barrios en que vivían, mediante el uso de cuestionarios y mapas mentales, a los que dio procesamiento estadístico, así como el análisis de mapas cognitivos (Muñoz, 2008). Para este trabajo se empleó un método cuantitativo (encuestas) y uno cualitativo (entrevistas), ya que ambas son "una ventana para aproximarse a los significados que los sujetos le otorgan a los lugares, a las prácticas espacializadas" (Lindón, 2008, p. 13), y están asociadas a interrogantes formuladas desde la perspectiva y la experiencia de las personas.

Las encuestas fueron llevadas a cabo en dos contextos diferentes, el primero, en temporada baja (75), en los alrededores del centro de la localidad; el segundo, durante la Feria Nacional del Mole (50), con la finalidad de conocer la procedencia de los visitantes a San Pedro Atocpan, sus principales motivaciones para ir, su percepción de la localidad con respecto a la ciudad, la forma en que se habían enterado del lugar como posibilidad de visita, y si el distintivo de Barrio Mágico Turístico había influido en la decisión de ir al lugar.

Conocer la percepción de las personas que

visitan San Pedro Atocpan resultó fundamental para saber si el lugar es, en su opinión, capaz de ofrecer atractivos que justifiquen el interés del gobierno -a nivel delegacional y estatal- en promocionarlo como sitio turístico, así como la relación de la localidad con la Ciudad de México; pero también resultó de suma importancia ver el panorama desde la perspectiva de la comunidad local, lo que dio paso a la formulación de un guion para entrevistas semi-abiertas (10) que permitieran saber un poco más de la cotidianidad del sitio, e indagar si el turismo forma parte del mismo.

En cuanto al análisis de la postura gubernamental, los datos fueron extraídos de documentos oficiales como el Plan Delegacional de Desarrollo Urbano y publicaciones del poder legislativo estatal, en los que claramente se hace alusión a las condiciones que podrían permitir la consolidación del turismo, además de folletos proporcionados por la oficina local de Promoción Turística. Un fragmento, extraído de un Boletín de la Asamblea Legislativa del Distrito Federal, refiere que

\begin{abstract}
(...) el pleno de la Asamblea Legislativa aprobó el Programa Delegacional Urbano de esa delegación [Milpa Alta]... Entre los objetivos fundamentales, resalta la propuesta de un programa de mejoramiento de poblados rurales dirigido a dar mayor proyección turística y cultural a eventos como la Feria del Mole. El programa permite la creación de corredores estratégicos, de carácter turístico, para mejorar o crear los espacios propios de las ferias locales (...) El documento prevé el impulso al desarrollo económico local, el mejoramiento de las condiciones de vida de la población y el respeto a la tradición cultural de sus habitantes, teniendo como marco de referencia su relación con la ciudad... (ALDF, 2011).
\end{abstract}

El documento anterior, junto con otros, vuelven evidente que la condición de vida de la delegación es diferente a la del resto de la ciudad, y se manifiesta una voluntad de mantener sus tradiciones, pero, por otro lado, se desea iniciar y consolidar una actividad turística centrada en el mole, lo que tal ve podría llegar a constituir en sí mismo un planteamiento contradictorio.

\section{Hallazgos relevantes}

En la primera muestra de visitantes (75), se hace evidente que más de la mitad proceden del sur de la ciudad $(61.33 \%)$, lo que permitiría inferir un área de influencia territorial a nivel zona. No obstante, pese a que podría parecer que tienen porcentajes de participación poco importantes, el hecho de que existan visitantes foráneos $(8 \%)$ y del 
extremo norte de la ciudad (4\%), implica que el área de influencia no es exclusiva para el sur, aunque dicha zona se aprecia como el principal emisor de visitantes.

Casi la mitad de los encuestados (47\%) indicó que el pueblo se encontraba lejos de la ciudad; mientras que una tercera parte lo percibió cercano a ella. En gran parte, quienes respondieron con esta última opción residen en Milpa Alta o en delegaciones aledañas. Por otra parte, quienes respondieron que el pueblo está aislado de la ciudad, en su mayoría fueron quienes llegaron de las delegaciones del norte o del Estado de México.

Un poco más de la mitad de los encuestados (35 de 75) refirió que San Pedro Atocpan está a una distancia considerable del centro de la ciudad; mientras que una tercera parte mencionó que el transporte no es adecuado. Otro factor importante fue el tiempo invertido en el viaje (16 de 75), así como la necesidad de atravesar Xochimilco o Tláhuac para llegar, pues suelen presentar tráfico muy denso debido a cierres viales por fiestas patronales (26 de 75). En general, la mayoría de los participantes veían poco atractivo el hecho de invertir una hora de viaje o más, aunque los habitantes del sur - y los del Estado de Méxicoparecen estar más habituados a trayectos similares.

El $97.33 \%$ de los encuestados definió la localidad como un pueblo, y la razón más importante para justificar su respuesta fue que la gran importancia dada a conservar sus tradiciones, en contraste con lo que suele vivirse en el resto de la ciudad; y una vez que los encuestados se enteraban de la condición de Barrio Mágico de la localidad (un dato poco conocido, incluso entre los lugareños), se buscó conocer si, en efecto, creían que San Pedro Atocpan poseía algún rasgo importante que justifique esa distinción. Cabe mencionar que tres cuartas partes de los encuestados afirmaron que sí lo merece; el resto no.

Los resultados muestran que, para los encuestados, tiene un gran peso saber que en San Pedro existen tradiciones que sus habitantes protegen y fomentan, así como el valor cultural que asocian con la tradición gastronómica de elaboración del mole. Otras razones importantes fueron que el lugar se percibe como bonito y tranquilo $(16 \%)$, y también que se perciba como un sitio dentro de la ciudad y a la vez muy diferente de ella $(10.66 \%)$, lo que refiere a una búsqueda por romper la cotidianidad. Por el contrario, quienes no consideraron que el lugar merece ese nombramiento mostraron indiferencia hacia sus rasgos $(18.66 \%)$ o cuestionaron que ahora muchos lugares sean etiquetados como mágicos (4\%), sin que quede claro el por qué.
Es importante analizar que el comportamiento de los visitantes fue diferente al de la encuesta hecha en "temporada baja". En ella, cerca de la mitad de los encuestados (44\%) refirió que acostumbra desde hace varios años-la mayoría indicó un mínimo de cinco años atrás; otros, más de quince- realizar una visita en cada Feria del Mole, mientras que una tercera parte acudió por primera vez, y el 24\% había ido en algunas ocasiones, pero no de manera continua.

De los encuestados de la segunda muestra (50), realizada en uno de los días de la Feria del Mole, 27 personas $(54 \%)$ hicieron referencia a que la Feria es el máximo atractivo del pueblo; incluso, muchas de ellas expresaron no conocer otra cosa importante de San Pedro además de dicho evento; 22 personas mencionaron que lo más atractivo son los restaurantes del pueblo, cuya especialidad es el mole, debido a que perciben un ambiente familiar y una mayor calidad del producto en esos lugares que durante la propia Feria.

En cuanto a la percepción del lugar respecto a la urbe, prácticamente las opciones de "cercano" y lejano" resultaron igualadas. La mayoría de quienes contestaron "cercano", viven en Milpa Alta o sus alrededores, y todas las personas de fuera de la ciudad respondieron lo mismo porque saben que el pueblo pertenece, administrativamente, a la Ciudad de México. En cambio, quienes respondieron "lejano", fueron los que emplearon más de hora y media para llegar, atravesaron grandes distancias, emplearon más de dos modalidades de transporte o superaron condiciones de tráfico intenso, condiciones que generaron una percepción negativa respecto de la conexión con el resto de la ciudad.

En el 36\% de los casos, lo que motivó a los visitantes para acudir a San Pedro fue la propaganda, presente tanto anuncios espectaculares en la carretera y en la ciudad, como en los microbuses de diversas rutas del sur de la ciudad; en segundo lugar, la motivación ocurrió por la recomendación de familiares y amigos $(32 \%)$ y el trabajo de instituciones y asociaciones civiles en grupos sociales concretos, en especial de adultos mayores $(18 \%)$. Finalmente, la televisión $(6 \%)$ y las redes sociales $(8 \%)$ fueron factores menos relevantes.

En cuanto a las entrevistas a locatarios y residentes, estructuradas con cuatro preguntas abiertas direccionadas a conocer la evolución de la actividad en torno al mole y la presencia de elementos que permitan inferir al consolidación de una actividad turística, los extractos más relevantes se resumen en el siguiente cuadro (los nombres de los entrevistados se omiten por temas de confidencialidad). 
En cuanto a la evolución de la localidad, la mitad de los informantes expresó que sí ha habido un cambio gradual, sobre todo en cuanto a la economía, pues se han dejado lentamente las

$$
\text { aqui, el mole, ser comerciantes". }
$$

Otros entrevistados también hicieron alusión a que históricamente, como pueblo, dejaron

Cuadro 1. Resumen de las opiniones vertidas por los entrevistados sobre el turismo en la localidad

\begin{tabular}{|c|c|c|c|}
\hline \multirow{4}{*}{$\begin{array}{l}\text { activid } \\
\text { ades } \\
\text { agrope } \\
\text { cuarias } \\
\text { para } \\
\text { dedicar }\end{array}$} & Percepción acerca del turismo en la localidad & \multirow{5}{*}{\multicolumn{2}{|c|}{$\begin{array}{r}\text { la } \\
\text { agricult } \\
\text { ura } \\
\text { para } \\
\text { ser } \\
\text { comerc } \\
\text { iantes, }\end{array}$}} \\
\hline & Restaurantes en fines de semana, pero no es algo muy promocionado o extraordinario & & \\
\hline & $\begin{array}{l}\text { Poco y mal planeado, las visitas guiadas no son de calidad. Mayor afluencia de visitantes en la } \\
\text { iglesia y los restaurantes }\end{array}$ & & \\
\hline & $\begin{array}{l}\text { Visitantes de fin de semana, pero es más importante el comercio que el turismo. Aun así sería } \\
\text { bueno promocionar más }\end{array}$ & & \\
\hline \multirow{6}{*}{$\begin{array}{l}\text { se de } \\
\text { lleno a } \\
\text { la } \\
\text { elabora } \\
\text { ción } \\
\text { del } \\
\text { mole y } \\
\text { comerc }\end{array}$} & Es una apuesta de la delegación, pero no se avanza como debería porque hay otras prioridades & & \\
\hline & Popularidad de los restaurantes en fin de semana y mayor proyección de la Feria del Mole & & \multirow{5}{*}{$\begin{array}{l}\text { y que } \\
\text { eso los } \\
\text { disting } \\
\text { uió del } \\
\text { resto } \\
\text { de los } \\
\text { pueblo } \\
\text { s de }\end{array}$} \\
\hline & La Feria se expande cada vez más, la gente busca un producto auténtico. Hay más empleo & & \\
\hline & Ha aumentado, debido a la calidad de la gastronomía, y eso deja empleo & & \\
\hline & Es bueno, llega gente de otros estados a conocer la comida, y eso deja buen dinero & & \\
\hline & $\begin{array}{l}\text { Muy bien, la gente se interesa cada vez más en conocer lo que como pueblo se vende, trae } \\
\text { empleos }\end{array}$ & & \\
\hline $\begin{array}{l}\text { io de } \\
\text { materia }\end{array}$ & $\begin{array}{l}\text { Como una oportunidad en cuanto a lo económico, así como de posicionar el producto a nivel } \\
\text { nacional }\end{array}$ & & \multirow{2}{*}{$\begin{array}{r}\text { Milpa } \\
\text { Alta, y } \\
\text { uno } \\
\text { más }\end{array}$} \\
\hline & & & \\
\hline
\end{tabular}

Quienes mencionaron no ver cambios en la localidad, en general, fueron los más jóvenes.

Un tema de gran relevancia para los habitantes de la localidad resultó ser la confianza. Los lazos comunitarios en San Pedro Atocpan son muy fuertes, incluso al punto de que, según un entrevistado, "nosotros terminamos haciendo las cosas que debería hacer la delegación". Varios entrevistados más refirieron que la gente es muy organizada, y que "hasta de nuestro propio bolsillo sale a veces para las cosas importantes, como las reparaciones de la iglesia, la fiesta de algún [santo] patrono o cosas de la Feria del Mole", lo que resalta los aspectos que consideran más importantes en su vida cotidiana.

En cuanto a las actividades económicas, los entrevistados en general mencionaron un cambio gradual. De acuerdo con uno de ellos,

\footnotetext{
"...hasta los sesentas, setentas (sic) aqui haciamos agricultura para nosotros; todos, o la mayoría, tenemos terrenos de labor en los cerros por nuestros abuelos, después esos terrenos los han comprado, los que vienen de Querétaro o de Toluca o de Oaxaca, y ya se quedan a trabajar acá... éramos campesinos, monteros, jornaleros, y viviamos del monte, del campo, de los que nos daba.

Viviamos del temporal. San Pedro ha trascendido la pobreza (sic) que anidaba en otros pueblos gracias a la industria del mole y al comercio, porque se trajeron de otros pueblos cómo se hacian las cosas, y las hicieron
}

hizo referencia a que buena parte de la iniciativa de los habitantes, para dedicarse a dichas actividades, fue tomada por las mujeres, que, al tener a sus esposos trabajando en el campo, decidieron aprender a preparar el mole y luego a introducir sus propias variantes para contribuir al ingreso familiar.

En este sentido, el mole es fundamental en la cotidianidad del pueblo, puesto que, de acuerdo con los habitantes, es por mucho la mayor fuen

te de empleo, aunque provoca posturas divididas. Por una parte, una parte de la población, en especial los jóvenes, ve en el mole un negocio redituable, mientras que el resto identifica al mole como una tradición arraigada en las familias, aunque parece predominar una concepción conciliatoria entre ambas posturas, en la que el mole se define como un platillo que se reinventa continuamente, que genera empleoy mantiene familias unidas.

Un tema de especial relevancia, surgido a lo largo de las entrevistas, resultó ser la escolaridad. Hay un contraste marcado entre quienes concluyen únicamente la secundaria, con la idea de ser sus propios patrones, y quienes buscan concluir una carrera para tener más posibilidades. El sentir general, entre las personas de mayor edad, puede sintetizarse en el siguiente extracto de una de las entrevistas:

$$
\text { "Aqui como que no nos cuadra esa idea [de }
$$


estudiar]. En San Pedro muchos dicen que no, los que tienen dinero dicen 'yo para qué quiero ir a la universidad, con mi lana, tengo a dos contadores y un abogado, y soy su patrón, y les mando'... Yo no soy universitario, para qué, de esa manera yo soy el patrón. Muchos lo dicen".

En cambio, las personas de menor edad refirieron que necesitan estudiar más para abrirse camino y no ser sólo los dependientes y empleados de los patrones, pero no están en conflicto con la idea de ser emprendedores; incluso, uno de los entrevistados refirió conocer gente con licenciatura o maestría que poseen algún negocio de mole. Este tópico parece ser un factor importante para la conformación de la identidad de los que se identifican a sí mismos como san pedreños.

La relación de San Pedro con la ciudad, desde el punto de vista de los entrevistados, es difícil en cuanto a infraestructura vial, y se hace un particular énfasis en el estado de las vías de comunicación: complicadas, caóticas por el constante cierre de calles, con tráfico y baches, son algunas de las descripciones que se hacen de las mismas. Asimismo, también resulta importante para los lugareños la diferencia que perciben en su localidad con respecto a la ciudad, un lugar más tranquilo, más citadino, más familiar, características que, según ellos, la distinguen hasta el punto de que los de otras delegaciones creen que somos provincia.

Algo que también resulta relevante en este aspecto es un sentido de pertenencia al pueblo, y que no se vive en otros sitios, según los entrevistados: uno refirió que, aunque no todos los comerciantes aguantan hacer tres o cuatro horas para vender sus productos, están arraigados al lugar; y otro expresó que

\section{“(...) algunos sanpedreños terminan asimilándose (sic) en otros lugares; pero terminan regresando, como se puede ver cada año, a finales. Porque tienen familia, porque tienen raices, y eso no es muy común en el resto de la ciudad".}

En cuanto al turismo, éste parece no acabar por repuntar como algo relevante en la localidad. Los entrevistados expresaron diversos puntos de vista al respecto, la mayoría de ellos positivos, pero no parecen darle una importancia especial: "estaría bien que se hiciera, pero hay otras cosas que hacer", "pues sí, viene gente los fines de semana, a ver la iglesia y a comer en los restaurantes, está bien", "han aumentado los comensales, porque saben que el mole de aquí es de gran calidad", son algunas de las expresiones vertidas por los entrevistados, en las que se hace evidente que el término turistas o turismo no está muy presente en la cotidianidad de San Pedro.

Se reconoce a la Feria del Mole como la mayor fuente de empleos, y como la máxima expresión de nuestro platillo, que puede posicionarnos a nivel nacional, pero en apariencia no se relaciona con la posibilidad de establecer una actividad turística consolidada en torno a una mística del mole. De acuerdo al encargado de la oficina de Promoción Turística, es una línea del Plan de Desarrollo que se

"tiene que expresar, como por inercia... pero falta una visión integral. San Pedro es Barrio Mágico no porque la delegación haya becho cosas, sino porque por sí mismo tiene algo qué mostrar. No lo hizo la autoridad, lo bicimos nosotros [como pueblo]".

\section{Conclusiones}

El análisis de discurso de los visitantes y locales entrevistados, sumado a la inexistencia de hoteles, agencias de viajes y otras instalaciones asociadas a la infraestructura turística en la localidad, ponen en entredicho el carácter de la actividad que se desarrolla en torno al mole, que las autoridades han etiquetado como turística. Asimismo, una posible integración de la localidad a la ZMVM a través del turismo se ve refutada por el gran número de opiniones que ven en sus tradiciones y su cotidianidad un fenómeno muy diferente de lo que se vive en la ciudad central. Incluso, diversos extractos dejan entrever que no consideran deseable esa circunstancia, pues se considera como valiosa la diferencia que existe entre la localidad y el resto de la ciudad.

Los residentes y locatarios entrevistados, así como los puntos de vista expresados por los visitantes, permiten entrever que el turismo en San Pedro Atocpan es una actividad suplementaria, pues se le otorga mayor importancia al comercio y a la llegada de consumidores a los restaurantes en temporalidades bien definidas -fines de semana y octubre, cuando se realiza la Feria- que a la recepción de turistas, que en general están más asociados al estereotipo del extranjero con la cámara fotográfica (Cohen, 2005) que a lo que la gente de la localidad percibe como comensales o visitantes, ya que realizan actividades con una duración menor a 24 horas, surgiendo así la cuestión de la temporalidad como una contraparte al discurso oficial, pues por sus características corresponde más a una actividad recreativa.

La actividad turística, de por sí con muchas aristas, se vuelve aún más difícil de analizar cuando 
ocurre en un espacio periurbano, que se ha convertido en una expresión territorial derivada de la reestructuración de los procesos contemporáneos (Sánchez, 2004), en el que los cambios se dan de manera aún más rápida que en los centros urbanos ya establecidos, pues suelen albergar mayor variedad de actividades económicas, dentro de las cuales la agricultura dejó de ser el eje articulador, pero sigue predominando una cotidianidad rural (Arias, 2005; Flores, Corona, Espinoza, Avilés, Juárez \& Garza, 2009).

En el caso particular de San Pedro Atocpan, de acuerdo con fuentes oficiales y corroborado por habitantes entrevistados, la economía hace cincuenta años dejó de girar en torno a la agricultura - presente aún en el resto de los pueblos de Milpa Alta- en favor de la industria del mole; y de acuerdo a fuentes institucionales, podría ser posible que al adoptar al mole como platillo distintivo de la localidad (lo que en 2011 se consolidó en el distintivo de Barrio Mágico Turístico), el turismo cobre mayor relevancia en la economía de la localidad.

También hay que considerar que las diversas disciplinas que analizan el fenómeno turístico han evidenciado que hay varias consecuencias-y no todas ellas de carácter económico- para los territorios en los que esta actividad se desarrolla. Algunas de ellas son los cambios sociales, que pueden provocar fragmentación por un enfoque empresarial, o cohesión al interior de la comunidad debido a la eliminación de desigualdades (Mosedale, 2016); culturales, ya sea en una revalorización de los atractivos, o una pérdida de identidad debido a la comercialización de los mismos (Delgadillo, 2015; Castañeda, 2012) e incluso ambientales (HigginsDesbiolles, 2006).

La relación estudiada entre turismo e integración a la metrópoli no permite formular una teoría concluyente. En primer lugar, el fenómeno parece responder más a las características de una actividad recreativa (Boullón, 1987) y no una turística, como refieren las autoridades en diversos documentos. En segundo, la ausencia de una categoría espacial definitiva para la localidad -que este trabajo fue definida como espacio periurbano, pero al ser un lugar en transición puede analizarse desde más categorías, como la de nueva ruralidad (Sánchez, 2004; Arias, 2005; Rivera \& Campos, 2008) - constituye una particularidad que puede derivar en grandes beneficios o perjuicios para la comunidad local debido a su alto dinamismo.

El trabajo de campo permitió contrastar la concepción del turismo que tienen los diversos niveles gubernamentales con la realidad que las personas viven de manera cotidiana o durante el tiempo destinado a visitar el lugar. En primer lugar, mostró que San Pedro Atocpan es un lugar muy atractivo para los habitantes de la zona sur de la ciudad, pero que poco a poco - en buena medida gracias a las campañas publicitarias de instancias gubernamentales- comienza a extender su área de influencia. Pese a ello, el nombramiento de Barrio Mágico Turístico no parece ser una razón de peso para motivar a potenciales visitantes, pues presumiblemente no ha tenido la difusión suficiente: incluso, los residentes señalaron que ni siquiera en la comunidad es un dato muy conocido.

De acuerdo con lo observado, la relación entre la localidad y el resto de la Zona Metropolitana del Valle de México es compleja. La poca accesibilidad dificulta un tránsito ágil de las personas que deben trasladarse desde o hacia San Pedro, además de que las rutas de transporte atraviesan delegaciones con vialidades congestionadas. No obstante, el intercambio comercial es intenso, si se toma en cuenta que el mole y las materias primas de San Pedro Atocpan están presentes en mercados de muchas delegaciones y en la Central de Abastos, pues el comercio se intensificó al verse beneficiado con la construcción de la carretera a Oaxtepec. Además, la función ambiental que cumple en general toda la delegación Milpa Alta - dentro de la cual se ubica San Pedro- es un aporte que no se puede olvidar, debido al rápido crecimiento urbano que pone en peligro las áreas rurales remanentes.

En cuanto a la actividad turística, es discutible si ésta existe en la localidad, pues cuenta con una estructura deficiente para albergar un fenómeno tan complejo como el turístico: no existen lugares para hospedarse, las vialidades suelen ser caóticas, los programas delegacionales en torno al turismo no tienen continuidad, aunque un enorme punto a favor es que la organización social que prevalece no ha perdido su sentido comunitario a pesar de la presión de la urbanización, y contempla con agrado, en general, el hecho de que la llegada de visitantes permita crear más empleos.

El hecho de que San Pedro sea un espacio periurbano con aspiraciones "turísticas" abre muchas posibilidades, pero también cuestionamientos. Un espacio periurbano posee mucha dinámica, por lo que tiende a cambiar, y casi siempre en favor de una condición cada vez más urbanizada, que parece entrar en conflicto con la preservación de costumbres y tradiciones de la localidad. Por otra parte, el turismo en espacios a las afueras de la ciudad tiende a causar que el sitio se transforme en lo que los visitantes quieren ver, alterando la cotidianidad de sus habitantes, lo que implica una transformación espacial y social que en 
ocasiones, lejos de fortalecer a la sociedad que alberga la actividad turística, la resquebraja, empezando por sus actividades económicas, que empiezan a sufrir una terciarización.

La actividad turística suele verse como un solución milagrosa para las economías locales (Dachary, 1991), pero han surgido casos muy específicos - como Venecia $\mathrm{v}$, en Italia- que demuestran que la planificación no es sólo deseable, sino necesaria, para que la economía no se unifique en torno a esa actividad y que a su vez el destino no supere su capacidad de carga. Por eso mismo, es imperativo señalar que existen abismos profundos entre la implementación de políticas turísticas en nuestro país; por ejemplo, las iniciativas federales de Pueblos Mágicos y Viajemos Todos por México son independientes de las estatales, como los Barrios Mágicos Turísticos, y de las delegacionales.

A nivel delegacional, las iniciativas turísticas en Milpa Alta se pierden o retrasan debido a que se prioriza el presupuesto disponible en sectores como el agroindustrial vi o el de desarrollo económico, pero en ocasiones son rescatadas e impulsadas por la sociedad organizada; incluso, la Feria del Mole fue ideada y organizada por primera vez exclusivamente por gente del pueblo, hasta después se dio apoyo por parte de la delegación, en el aspecto logístico.

Si bien, el origen de la adopción del mole como platillo representativo en la localidad es incierto, permitió que familias originarias dejaran la pobreza y se convirtieran en sus propios patrones: de ahí la rápida expansión del mole como negocio, cuya máxima expresión es la Feria del Mole. Hasta ahora, esta actividad se ha utilizado como argumento para intentar consolidar el lugar como sitio turístico, pero existen cuestiones que no se han tomado en cuenta, una de ellas, que el crecimiento de Milpa Alta es el mayor de todo el Valle de México (INEGI, 2015), y este poblado en particular, que genera un alto número de empleos con la industria del mole, podría verse presionado; otra razón podría ser un posible aumento en el interés por el turismo cultural.

La gastronomía del pueblo puede posicionarlo en el mapa turístico de la Zona Metropolitana del Valle de México. Pero algunas preguntas que tendrían que responderse antes de que esto ocurra son: ¿Es deseable desarrollar actividades recreativas $-O$ turísticas- en espacios tan frágiles como los periurbanos? ¿El turismo podría llevar la urbanización definitiva a San Pedro, algo contra lo que los lugareños han tenido que luchar desde la expansión de la ciudad?

\section{Notas}

i Commodities es el término con el que se denomina a aquellos bienes o servicios que solían ser brindados por el Estado y su suministro o existencia ahora está en manos de empresas privadas, más allá de su definición de diccionario, mercancía. Para más información de esta acepción, consultar Breve historia del neoliberalismo, de David Harvey.

ii La población local refiere diversos orígenes del platillo en su localidad: mientras unos refieren que fue introducido por un sacerdote poblano, otros hablan de una familia acomodada que lo trajo desde Cholula. Fuente: Trabajo de campo, agosto-octubre de 2016.

iii La población local refiere diversos orígenes del platillo en su localidad: mientras unos refieren que fue introducido por un sacerdote poblano, otros hablan de una familia acomodada que lo trajo desde Cholula. Fuente: Trabajo de campo, agosto-octubre de 2016.

iv Consultar nota periodística de La Jornada, En San Pedro Atocpan, 92\% de la población se dedica a la preparación y venta del mole, disponible en el link http://www.jornada.unam.mx/2007/09/23/index.php? section $=$ capital $\&$ article $=035 \mathrm{n} 1 \mathrm{cap}$. Si bien es una nota de 2007, es una tendencia que, según censos económicos, persiste hasta hoy.

$\checkmark$ Para este particular, puede consultarse Turismo y medio ambiente en ciudades históricas: de la capacidad de acogida turística a la gestión de los flujos de visitantes, de María García Hernández (2000), en donde se habla de los problemas ecológicos y patrimoniales causados por la afluencia masiva de turistas a Venecia.

vi Información obtenida en una entrevista, concedida por el Prof. Saúl Ríos Flores, encargado de la oficina de Promoción Turística de la delegación. 


\section{Referencias bibliográficas}

Arias, P. (2005). Nueva ruralidad: antropólogos y geógrafos frente al campo hoy. In H. A. Sánchez (Coord.). Lo urbano-rural, ¿nuevas expresiones territoriales? (pp. 123-159). Cuernavaca, México: UNAM-CRIM.

Asamblea Legislativa del Distrito Federal ALDF, (2011). Aprueba ALDF nuevo Programa Delegacional de Desarrollo Urbano de Milpa Alta. Boletín núm. 224, 31 de marzo de 2011. Recuperado el 7 de diciembre, 2017, de http://www.aldf.gob.mx/comsocaprueba-aldf-nuevo-programadelegacional-desarrollo-urbano-milpaalta--7407.html

Blanco, A. D. R. (2017). El turismo como factor de integración de un espacio periurbano a la metrópoli: El caso de San Pedro Atocpan (Tesis de licenciatura). Universidad Nacional Autónoma de México, México.

Boullón, R. (1987). Las actividades turísticas y recreacionales. Argentina: Trillas.

Castañeda, Q. (2012). The neoliberal imperative of tourism: rights and legitimation in the UNWTO global code of ethics for tourism. Practicing Anthropology, 34 (3), pp. 47-51. Recuperado de http://www.oseacite.org/class/quetzil/Quetzil2012 Neo liberal Tourism_Imperative.pdf

Cohen, E. (2005). Principales tendencias en el turismo contemporáneo. Política $y$ sociedad, 42 (1), pp. 11-24.

Consejo Nacional para la Cultura y las Artes CONACULTA (2013). Politicas públicas y turismo cultural en América Latina: siglo XXI. México: CONACULTA.

Contreras, T. C. \& Muñoz, A. P. (Coords.) (2014). Complejidad del turismo en la frontera del conocimiento. México: Gasca.

Custardoy, M. T. L. (2003). La morada de los dioses. Sistemas de cargos en Milpa Alta (Tesis de licenciatura). Universidad Nacional Autónoma de México, México.

Dachary, A. (1991). Los impactos del turismo y sus alternativas. El caso de San Pedro Ambergris, Belize. México: CIQRO.

Delgadillo, V. (2015). Patrimonio urbano, turismo y gentrificación. In V. Delgadillo, I. Díaz, Ibán \& L. Salinas (Coords.). Perspectivas del estudio de la gentrificación en México y América Latina (pp. 113-132). México: UNAM-Instituto de Geografía.

Equipe MIT (2002). Tourisme 1: lieux communs. París: Belin.
Fernández, B. (2016). La politica del turismo cultural en México. El caso del programa Pueblos Mágicos. (Tesis de maestría). Universidad Nacional Autónoma de México, México.

Flores, J. A. H., Corona, B. M., Espinoza, J. A. M., Avilés, R. P., Juárez, J. R., \& Garza, H. N. (2009). Rurales y periurbanos: una aproximación al proceso de conformación de la periferia poblana. Papeles de población, 15 (61), 275$295 . \quad$ Recuperado de http://www.scielo.org.mx/scielo.php?sc $\underline{\text { ript }}=$ sci arttext\&pid $=\mathrm{S} 14057425200900$ 0300011\&lng=es\&tlng $=\mathrm{es}$

Fraga, J., Khafash, L. \& Ordoñez, J. C. (2015). Turismo y ocio: mercantilización y consumo de espacios, lugares, objetos y emociones. In J. Fraga, J., L. Khafash, \& J. C. Ordoñez (Coords.) Turismo y ocio: Reflexiones sobre el Caribe Mexicano. (pp. 25 - 43). Tenerife: Pasos. RTPC.

Hernández, M. G. (2000). Turismo y medio ambiente en ciudades históricas: de la capacidad de acogida turística a la gestión de los flujos de visitantes. Anales de Geografía de la Universidad Complutense, (20), pp. 131-148. Recuperado de http://www.tuciudadcolonial.do/aplicac ion/attachments/article/159/CCC VI Mpdf.pdf

Higgins-Desbiolles, F. (2006). More than an industry: The forgotten power of tourism as a social force. Tourism management, 27 (6), pp. 1192-1208. Recuperado de https://doi.org/10.1016/i.tourman.200 $\underline{5.05 .020}$

Hursh, K. (2008). October in Actopan: Mexico's National Mole Festival. Recuperado de http://www.mexconnect.com/articles/ 2945-october-in-actopan-mexico-snational-mole-festival

Instituto Nacional de Estadística, Geografía e Informática - INEGI (2015). Encuesta Intercensal 2015.

Instituto Nacional para el Federalismo y el Desarrollo Municipal - INAFED (2005). Enciclopedia de los municipios y delegaciones de México.

Lindón, A. (2008). De las geografías constructivistas a la narrativas de vida espaciales como metodologías geográficas cualitativas. Revista da ANPEGE, (4), pp. 6-26. Recuperado de http://www.anpege.org.br/revista/ojs2.4.6/index.php/anpege08/article/view $\angle 8 / 0$ 
Lynch, K. (1998). La imagen de la ciudad (3a ed.). Barcelona: Publicaciones Gustavo Gili.

Mosedale, J. (2016). Tourism and neoliberalism: states, the economy and society. Neoliberalism and the political economy of tourism. UK: Ashgate.

Muñoz, J. L. V. (2008). Cinco The tourist gaze. London décadas de Geografía de la percepción. Ería, (77), pp. 371-384.

Nash, D. (1992). El turismo considerado como una forma de imperialismo. In Smith, V. (Ed.). Anfitriones e invitados (Antropología del turismo), (pp. 69-91). Madrid: Endymion.

Nicolas, D. H. (2006). Geografía del turismo. In D. H. Nicolas \& A. L. Villoria. Tratado de geografía humana. (pp. 401 - 132). México: Anthropos.

OMT (2012). Tourism. In Glossary of terms. Recuperado http://www2.unwto.org/es

Picard, D. (2011). Tourism, magic and modernity. Oxford: Berghahn Books.

Plan Delegacional de Desarrollo Urbano de la delegación Milpa Alta - PDDU (2011).

Rivera, N. R. \& Campos, J. D. (2008). Territorio $\mathrm{y}$ nuevas ruralidades: un recorrido teórico sobre las transformaciones de la relación campo-ciudad. Eure, 34 (102), pp. 70-90. Recuperado de http://dx.doi.org/10.4067/S025071612008000200005

Sánchez, H. A. (2004). Agricultura, periurbanización y nueva ruralidad. Revista de Geografía Agrícola, 33, pp. 23-46. Recuperado de https://chapingo.mx/revistas/revistas/ articulos/doc/rga-646.pdf

Secretaría de Turismo (SECTUR, 2001). Bases de operación del Programa Pueblos Mágicos. Recuperado de www.dof.gob.mx/nota detalle.php?codi $\mathrm{go}=5361690 \& \mathrm{fecha}=26 / 09 / 2014$

Sizzo, I. A. (2012). El espacio subjetivo de la ciudad de Morelia en relación a su Centro Histórico y el turismo cultural. Un estudio de percepción e imagen (Tesis de doctorado). Universidad de Castilla-La Mancha, España.

Soneiro, J. C. (1991). Aproximación a la geografía del turismo. Madrid: Síntesis.

Sue, R. (1987). El ocio. México: Fondo de Cultura Económica.

Turner, L. \& Ash, J. (1991). La horda dorada. El turismo internacional y la periferia del placer. Madrid: Endymion.

Urry, J. (2002). The tourist gaze (2a ed.) .London: Sage Publications.

Velázquez, B. R. R. (2002). La vieja agricultura y la nueva ruralidad: enfoques y categorías desde el urbanismo y la sociología rural. Sociológica, 18 (51), pp. 49-71. Recuperado de http://www.sociologicamexico.azc.uam. $\mathrm{mx} /$ index.php/Sociologica/article/view File/394/370

Vich, V. (2006). La nación en venta: bricheros, turismo y mercado en el Perú contemporáneo. In A. Ypeij \& A. Zoomers (Eds.). La ruta andina: turismo y desarrollo sostenible en Perú y Bolivia (pp. 187-196). Perú: Abya Yala.

Vinuesa, M. A, T., Marchante, J. S. G. \& Hernández, M. G. (Coords.) (2008). Destinos turísticos: viejos problemas, ¿nuevas soluciones? España: Universidad de Castilla-La Mancha.

Wacher, M. (2006). Nabuas de Milpa Alta. México: Comisión Nacional para el Desarrollo de los Pueblos Indígenas.

\section{Cómo citar este artículo}

Rodríguez, A. D. (2018). Perspectivas do turismo no Bairro Mágico San Pedro Atocpan em função da sua condição de espaço periurbano. PatryTer, (1), 1, pp. 68-80.

DOI: https://doi.org/10.26512/patryter.v1i1. $\underline{5805}$ 